DOI 10.37882/2500-3682.2021.04.04

\title{
ПОСТРОЕНИЕ ПРОФЕССИОНАЛЬНОЙ ИДЕНТИЧНОСТИ В СЛОЖНЫХ УСЛОВИЯХ СТАЖИРОВКИ УЧЕНИКОВ В СФЕРЕ РОЗНИЧНОЙ ТОРГОВЛИ В АЛЖИРЕ
}

\section{BUILDING A PROFESSIONAL IDENTITY DESPITE CHALLENGING WORKING CONDITIONS: RETAIL APPRENTICES IN ALGERIA}

\section{K. Budaud}

Summary: This article analyzes the working conditions experienced by retail trainees during their education and how these working conditions influence the formation of professional identity. We propose to explore, through qualitative survey based on observations, interviews and group discussions, how students learn and what role working conditions play in their identification with work. The analysis identified four aspects that the students faced: work intensity, time availability combined with socioeconomic insecurity, company social relationships, and customer relationships.

Keywords: professional education, working conditions, socialization, vocational identity.

\section{Введение}

$\Pi$ рофессия продолжает играть определенную роль в социализации индивидов (Дармон, 2016; Dubar, 1998b), хотя это уже не считается уникальной и стандартизирован социальной моделью. Опыт, приобретенный, в частности, во время обучения, трансформирует не только знания, но и личность обучаемых. Таким образом, процесс обучения - это не просто приобретение профессиональных ноу-хау и навыков межличностного общения, но также процесс конструирования смысла своего опыта и самого себя (Kaddouri, Lespessailles, Maillebouis, \& Basconcellos, 2008; Zittoun, 2016). В этом контексте профессиональная идентичность - это как индивидуальный, так и социальный проект (Dubar, 1998b), который развивается в соответствии не только с собственными интересами и ресурсами, но также с требованиями и ограничениями, встречающимися в мире труда.

Эта статья, основанная на социологическом исследовании с участием стажёров в розничной торговле в Алжире, предлагает проанализировать предпосылки построения профессиональной идентичности, обсудив роль условий труда. Как показал опрос, эти условия оказались одной из основных проблем определения профессиональной идентичности для учеников. Такой под-
Будауд Карим

Аспирант, Казанский федеральный университет, Казань K-Budaud@stud.kpfu.ru

Аннотация: эта статья посвящена анализу условий труда, в которых находятся стажёры розничной торговли во время обучения, и как эти условия влияют на формирование профессиональной идентичности. Мы предлагаем результат исследования, полученный с помощью качественного опроса, наблюдений, интервью и групповых обсуждений, как стажёры проходят обучение, и какую роль условия труда играют в их профессиональной идентификации. В результате анализа были выявлены четыре аспекта, с которыми сталкиваются ученики на практике: интенсивность работы; продолжительный ненормированный рабочий день или неполный рабочий график в сочетании с социально-экономической незащищенностью; социальные отношения В компании; отношения с клиентами.

Ключевые слова: профессиональное образование, условия труда, социализация, профессиональная идентичность.

ход позволяет ставить под сомнение хорошие и плохие условия на основе субъективных точек зрения тех, кто сталкивается с ними ежедневно, облегчая или препятствуя построению их профессиональной идентичности. Таким образом, вопрос анализа того, как ученики развивают профессиональную идентичность в текущем рабочем контексте, отмеченном гибкостью занятости и часто индивидуализированной профессиональной карьерой, остается центральной проблемой, особенно для их будущего на рабочем месте в профессиональном мире.

Мы предлагаем теоретическое размышление и эмпирический анализ связи между началом построения профессиональной идентичности и условиями работы в розничном секторе. Для этой профессии характерны довольно сложные условия труда - продолжительный и ненормированный рабочий день, работа в выходные и в вечерние часы, постоянный контакт с клиентами и нестабильность, в частности, из-за довольно низкой заработной платы и неполной занятости. Принимая во внимание эти характеристики, будет показано, что ученики развивают амбивалентные отношения со своей профессией, колеблющиеся между приверженностью-проекцией и стремлением к профессиональному дистанцированию-переориентации. 
В первую очередь будет определена теоретическая основа данного исследования. Затем будут кратко представлены ученичество менеджера розничной торговли в Алжире в рамках подготовки работы-исследования, а также методы сбора и анализа используемых данных. Наконец, будут проанализированы условия труда учеников, чтобы показать их влияние на развитие профессиональной идентичности.

\section{Формирование профессиональной идентичности через условия труда}

Знакомство с профессиональной средой в рамках производственного обучения подразумевает эволюцию учеников, в частности, трансформацию их знаний в новые знания, которые они приобретают в своей профессиональной деятельности и их профессиональной идентичности. Дубар (1998b) предлагает для изучения карьерного пути и профессионального развития принимать во внимание двойной компонент профессиональной идентичности. По его словам, это определяется биографическим компонентом: человек конструирует свою идентичность в соответствии со своим прошлым, ожиданием будущей траектории занятости и, в более широком смысле, своими прогнозами на будущее; Каддури (2006) говорит об унаследованных идентичностях и предлагаемом проекте идентичности. Другой, так называемый, реляционный компонент, напоминающий идентичности, полученный от Каддури (там же), возникает в результате взаимодействия с социально-профессиональной средой и формами идентичности, предлагаемыми другими участниками в профессиональной сфере, а также связанными с ними властными отношениями.

Эти разные характеристики означают, что профессиональная идентичность не фиксирована. Он меняется в зависимости от опыта и социального положения, которое может иметь человек, требуя постоянных корректировок, чтобы он мог найти определенный баланс между идентичностью для себя и для других (Jenkins, 2008). Kaddouri (2006, стр. 122) говорит о динамике идентичности в том смысле, что идентичность - это «процесс в постоянном строительстве, деконструкции, реконструкции», относящийся к прогрессу, а не к «закрытию». B самом центре отношений на рабочем месте (Fray \& Picouleau 2010) предлагает в своей концепции профессиональной идентичности принимать во внимание три основных элемента, через которые будут играть роль условия труда:

— жизненный мир труда - это объективная рабочая ситуация;

- рабочие отношения, воспитывающие чувство принадлежности к неформальным группам;

- профессиональные траектории, связанные с восприятием будущего.
Анализ условий труда оказался подходящим подходом для понимания развития профессиональной идентичности в конкретной работе и рабочем контексте. В формировании профессиональной идентичности условия труда играют преобладающую роль, особенно в начале профессиональной карьеры. Условия труда заставляют человека подвергнуть сомнению свою идеальную профессиональную модель и познакомиться с реальным профессиональным контекстом, подразумевая корректировку самой концепции своей личности в процессе конструирования (Dubar, 1998a). Однако основная проблема идентичности для человека заключается в нахождении баланса (Kaddouri, 2006) между его собственными профессиональными ожиданиями (идентичность для себя) и ожиданиями рабочего мира (идентичность для других). Если баланс остается труднодостижимым, под сомнение ставится построение позитивной профессиональной идентичности.

Чтобы провести собственное исследование роли условий труда в развитии идентичности, мы использовали материалы исследований, проведенных в области розничной торговл (Alonzo, 1998), а также, в целом условий труда (Gollac, Volkoff, \& Wolff, 2014), и, в частности, с категоризацией психосоциальных рисков (Mercure, Wultur, 2010). При анализе выделены шесть параметров:

- требования и интенсивность работы, которые объединяют количество и сложность работы, нехватку времени и ритм (Charmaz K, 2010, p. 2);

- эмоциональные требования, вынуждающие служащего контролировать и формировать свои собственные эмоции, одновременно принимая на себя эмоции бенефициаров их работы (Hochschild, 1983);

- социальные и рабочие отношения, которые могут вызвать признание и чувство полезности для проделанной работы;

- социально-экономическая незащищенность, ставящая под угрозу устойчивость положения в сфере занятости;

- непостоянный рабочий график (переработка или неполный рабочий день), характерный для розничной торговли.

\section{$\triangle$ войное обучение по методологии розничной торговли и опросов}

В Алжире обучение менеджеров розничной торговли является вторым по важности (в 2016 году обучение прошли 4083 слушателя из 70148 человек). Основное внимание в трехлетней программе обучения уделяется продажам, консультированию клиентов и управлению продуктами. Он проводится в профессионально-техническом училище в течение 30 месяцев, и студенты проходят обучение параллельно в компании один день в неделю в течение 6 месяцев. Обучение дополняется 
10-дневными межфирменными курсами, организуемыми профессиональными ассоциациями, целью которых является передача и получение базовых знаний.

Из-за изменений в отрасли, таких как разработка новых методов продаж или покупки в Интернете, будущее профессии остается неопределенным. За последние два десятилетия произошло резкое усиление конкуренции, что вынудило компании сокращать расходы в ответ на эту экономическую неопределенность. Таким образом, часто вводится неполный рабочий день, чтобы более гибко реагировать на потоки потребителей. К этому добавляется давление на законодательные ограничения на часы продаж, которые становятся все более гибкими. Эти различные характеристики подразумевают необходимость адаптации обучения, особенно к цифровым технологиям, и могут нарушить построение личности ученика во время обучения.

Результат нашей работы основан на исследовании, проведенном в трех профессиональных школах с четырьмя классами, три из которых находятся на первом курсе, а один - на третьем. Он основан на качественных методах с фокус-группами (4), наблюдениях в классе и во время перерывов (примерно 12 дней в классе), что позволило углубить опрос полуструктурированными интервью, проведенными с 25 учениками в возрасте от 16 до 22 лет (11 мужчин и 14 женщин). В конце исследования были организованы новые фокус-группы в 6 классах 3-го года обучения (включая 3 класса, за которыми следовали первоначально) с целью обсуждения результатов анализа с будущими выпускниками.

Опрос учеников об их обучении и опыте работы в компании, их имидже профессии или даже их карьерных планах позволил провести критический анализ ситуаций, возникающих в ходе их обучения (Mercure \& Vultur, 2010). Эмпирический материал был полностью переписан. Для обработки опроса была выбрана методология, представленная в работе «Обоснованная теория» (Charmaz, 2001), чтобы быть ближе к интересам учеников. В процессе обработки было выявлено, что условия работы представлялись ученикам как реальные проблемы с идентификацией.

\section{В^ияние условий труАа на построение профессиональной ихентичности}

В зависимости от сектора продаж (пекарня, магазины одежды, спорт и т.д.) или типа бизнеса (независимый бизнес, сеть магазинов и т. д.) условия труда могут восприниматься учеником по-разному. Однако мы не будем принимать во внимание эти различия, поскольку данные не отражают чётко тенденций по отраслям продаж, типу или размеру бизнеса. Вот почему этот анализ в основном фокусируется на сходстве опыта, чтобы понять, как эти молодые люди чувствуют и переживают свои условия работы в компаниях, обстановку, в которой они формируют свою идентичность.

Анализ позволил выявить четыре аспекта, с которыми сталкиваются ученики, которые облегчают или препятствуют построению их профессиональной идентичности:

- потребности и интенсивность работы;

- временные ограничения в сочетании с социально-экономической незащищенностью;

- социальные отношения и поддержка внутри компании;

— отношения с клиентами.

\section{Требования и интенсивность работы: ставка на признание ученика}

Ученики считают, что они должны быть чрезвычайно разносторонними и гибкими в выполнении своих задач, а также в управлении многими ситуациями в чрезвычайных обстоятельствах. Несмотря на наличие иногда свободного времени, работа обычно воспринимается как стрессовая, особенно в определенные периоды, такие как выходные или в конце года, или в периоды сильной загруженности. Если место работы расположено далеко от дома, то ежедневные поездки «туда-обратно» повергают работника ежедневному стрессу от дороги, будь то в общественном или личном транспорте.

Первокурсница Кахина на стажировке в супермаркетах DIY в отделе садоводства, изначально мотивированная своим профессиональным выбором, демонстрирует негативное отношение к профессии при сильной загруженности: «Да, сначала у меня было радостное чувство, я была очень сильно мотивирована и действительно приступила к работе с улыбкой. Но сейчас, весной, я работаю в стрессовой ситуации, когда все бросились в магазины, готовясь к летнему сезону, я не думала, что это будет настолько экстремально. Имея одновременно много дел, я вынуждена работать без перерыва ».

Реальность работы в этом секторе продаж вызывает демотивацию или даже дистанцирование, но в данном случае это не препятствует идентификации с профессией. Скорее всего, Кахина будет рассматривать возможность смены компании после стажировки, чтобы улучшить условия труда.

Хотя интенсивность и тяжесть физического труда часто упоминаются и критикуются учениками, они не всегда воспринимаются отрицательно. Это также, в определенной степени, средство ознакомления с реальностью мира труда, тем самым укрепляя их чувство принадлежности или даже идентификации с профессиональной сферой. 
Временная доступность и социально-экономическая незащищенность: проблема признания частной жизни и профессионального статуса

Часто работодатели и работники называют ограничивающими и сложными условиями труда, ненормированный рабочий день или гибкий график работы регулируются по-разному, в зависимости от компании. Некоторые ученики сильно напрягаются от ненормированного графика, работая по субботам или поздно ночью, иногда с ощущением того, что работодатель их эксплуатирует. Кахина, несмотря на свое призвание к профессии продавца в секторе DIY и садоводства, не хочет оставаться в своем бизнесе и подчеркивает отсутствие признания ее доступности и приверженности:

«Иногда я действительно работаю... с 9: 45 до 22 часов. Так быть не должно. Но никто не проверяет, это нормально, и никто не скажет: «О, спасибо, что задержались вчера еще немного». Всегда оценивается немного меньше, чем я сначала думала об этом».

Конфронтация с профессиональным миром через гибкий график может быть трудной для учеников, особенно в начале обучения, потому что это означает определенный разрыв с их прежней жизнью. Ещё больше негативное влияние гибкий график оказывает на личную жизнь, подрывая социальную и семейную жизнь из-за отсутствия свободного времени. Самоидентификация, которая не только профессиональна, но и связана с семьей, друзьями или отдыхом, также трудно согласовать с ожиданиями профессионалов в сфере продаж.

Условия оплаты труда - фактор риска, поскольку в случае незащищенности они снижают чувство контроля над ситуацией, а также самооценку - не воспринимаются положительно, учитывая, среди прочего, трудность задачи делать прогноз об оплате труда в сфере розничной торговли. Таким образом, профессиональная идентичность окажется под угрозой, потому что под сомнение будут поставлены будущая возможность трудоустройства и прогноз будущей жизни.

Цилия, ученица третьего курса, резюмирует это следующим образом: «Люди не понимают, что психологически это ограничивает, возможно, даже потребуется, чтобы заработная плата была выше, потому что таких людей, которые захотят выполнять эту работу, будет меньше».

Иногда встречаются ученики с высшим образованием, или имеющие родителей с высшим образованием, которые критикуют соотношение между работой и заработной платой. Янис, например, проходит первый год стажировки в телефонном магазине, он убежден, что не топ-менеджеры, а служащие на нижних уровнях иерархии в основном формируют оборот компании, но не по- лучают адекватной зарплаты. Янис, как и многие другие ученики, рассматривает социальную мобильность внутри или за пределами своей компании для улучшения своего материального положения. Таким образом, тяжелые условия труда делают эту профессию, даже если ученики любят и ценят её, проблемным профессиональным контекстом.

\section{ПодАержка и сошиальные связи внутри компании: вопрос признания полноправным членом}

Позитивная атмосфера в компании, которую иногда называют «семьей», играет решающую роль в отношениях, которые ученик устанавливает с профессией. Сплоченная команда, способствующая взаимопониманию, позволяет ученику занять своё место в компании и, следовательно, чувствовать себя полезным и привязанным к организации, что способствует формированию его идентичности, а также принятию других условий работы, таких как интенсивная загрузка и решение трудных задач. Таким образом, хороший коллектив становится убежищем или даже защитой от трудовых ограничений.

Салим, ученик первого курса, работающий в магазине крупного спортивного бренда, явно ценит качество этих отношений: «Мне нравится команда и люди, с которыми я работаю, потому что здесь действительно отличная атмосфера; это действительно команда, где мы можем помогать друг другу, где, если у нас есть вопросы, по крайней мере, сотрудники на них отвечают, они помогают нам».

Кроме того, хорошие отношения с тренером в компании обнадеживают и мотивируют. Напротив, отсутствие признания и внимания может породить разочарование с риском нарушения контракта. Билал, ученик 3-го курса, работающий в киоске, попал в очень трудные условия обучения, в том числе из-за плохого надзора и смены компании до такой степени, что в конце обучения у него возникли смешанные чувства к своей профессии. Возможно, если бы он попал в более дружелюбную учебную среду, он смог бы оценить положительные стороны своей профессии. Во время 2-й фокус-группы он не решился сменить работу, проходя обучение в качестве сотрудника отдела продаж. Его новая, более благоприятная учебная среда побудила его продолжать работать по профессии.

Сложность часто возникает, когда тренер присутствует недостаточно или личность тренера чётко не определена. Сабрин, ученица первого курса, проходящая стажировку в отделе парфюмерии, испытывающая дискомфорт от плохой организации в своей компании, часто сама должна решать трудности в своей повседневной работе. Она страдает от недостатка руководства своей работой и говорит, что ей «нужны четкие инструк- 
ции», особенно когда её коллеги добавляют задачи, и ей трудно расставлять приоритеты. Сабрин была одной из самых молодых учениц, и до обучения у неё было очень мало опыта работы. К тому же она не представляет своего профессионального будущего в профессии.

Отсутствие признания навыков ученика может даже привести к заниженной самооценке у некоторых. Это случай Али, ученицы 3-го курса ювелирного дела, которой трудно справиться со своей деловой ситуацией: «Так что, чувствуя себя учеником, мы на самом деле чувствуем себя более или менее ниже других, иерархически мы выше разве только дворника».

Коэн-Скали иллюстрирует этот парадокс: «Переключенные между своей ролью ученика, но также и производственного агента, практиканты имеют особый и часто неоднозначный статус в компании. Расположенные по большей части на самом нижнем уровне корпоративной иерархии, они кажутся особенно уязвимыми. Их позиция открывает двери для форм стигматизации и дисквалификации, которые часто являются источниками страданий, которые могут оказаться особенно катастрофическими в тот период, когда построение идентичности представляет собой серьезную проблему для развития »(Cohen-Scali, 2001, с. 217).

Хотя анализ показывает важность социальной поддержки и надзора, его отсутствие парадоксальным образом позволяет в определенных ситуациях развивать профессиональную идентичность, поощряя принятие ответственности и инициативу. Таким образом, это стремление к самостоятельности укрепляет оценку своих навыков и имидж себя как профессионала.

\section{Отношения с кАиентами: ставка на признание себя как профессионала в области продаж}

Отношения с клиентами, относящиеся к эмоциональным требованиям, кажутся важными для развития профессиональной идентичности. Работник сферы услуг должен контролировать и формировать не только свои собственные эмоции, но и эмоции бенефициаров их работы. Любые служебные отношения связаны с проблемами власти и признания, которые иногда превращаются в борьбу (Gadrey et al., 2005). Неприятное отношение со стороны клиентов может особенно повлиять на ощущение тяжелой работы и нарушить идентификацию с работой.

Опрошенные ученики отмечают иногда противоречивые отношения с клиентами и их невнимание, что может быть одной из причин профессиональной переориентации. Камел, ученица третьего курса ювелирного дела, столкнувшись с роскошной клиентурой, которая часто обращается с ними как с подчиненными, говорит об этом так: «Если бы не было клиентов, это была бы лучшая работа в мире!».

Эти результаты напоминают классические исследования эмоциональной работы в сфере обслуживания, которые показывают, что управление эмоциями может вызывать отчуждение от работы или даже выгорание (Hochschild, 1983). Тем не менее, анализ также согласуется с современными исследованиями, которые подчеркивают, что женщины-служащие в службе также могут ценить отношения с клиентами, позволяя им не только поднять самооценку, но и развивать личные навыки, важные для этой службы. Контакт с клиентами становится важным условием работы, потому что ученики получают здесь признание как профессионалы в области продаж, что укрепляет их в их выборе и, в более общем плане, в открытии бизнеса.

\section{ОбсужАение}

Вопрос о формировании профессиональной идентичности в процессе обучения профессии, характеризующейся сложными условиями труда, показал, насколько важен аспект отношений. Социальное признание - источник смысла и удовольствия от работы (Dejours, 2000) - ключевое слово в этом анализе, поощряет конструирование личности ученика, который ощущает свою ценность в коллективе. Таким образом, идентичность для себя и идентичность для других неизбежно переплетаются и зависят друг от друга. Мы согласны с Fray \& Picouleau (2010), которые отводят важное место работе в определении идентичности, поскольку оно обеспечивает признание, которое позволит определить место, которое человек отводит работе в определении себя.

Таким образом, смысл работы заключается в отношениях, которые ученик устанавливает со своими коллегами, и в чувстве коллективной принадлежности, которое он или она разовьет во время обучения. Социальные отношения внутри компании, таким образом, являются фактором поддержки в профессии не только из-за необходимости признания в качестве полноправных членов, но и для получения поддержки и совета в качестве ученика. Таким образом, хорошее качество этих отношений сделало бы профессиональные трудности более терпимыми. В большинстве случаев условия труда определяются иерархией в компании и коллегами, даже если последние недостаточно осознают потребности ученика. Это во многом связано с сильной конкуренцией в сфере продаж, которая часто оказывает давление на руководителей и сотрудников.

Отношения с клиентами - реальный вопрос признания профессионала в области продаж и внедрения в торговлю - также играет роль в развитии профессиональной идентичности. Эмоциональные требования 
этих отношений представляют собой серьезную проблему для учеников, которая иногда позволяет им почувствовать себя ценными экспертами по продажам, а иногда побуждает их переориентироваться в профессиональном плане, если эти отношения становятся слишком унизительными.

Другие факторы, такие как напряженное рабочее время, как правило, осложняют отношения с работой, создавая напряженность в личной и профессиональной сферах. Отсутствие внимания к частной жизни особенно трудно для учеников, впервые вступающих в мир труда и в секторе, который требует большой гибкости. Кроме того, рабочее время в сочетании с низкой заработной платой и неполной занятостью затрудняет внедрение в профессию. Страх перед социально-экономическим будущим присутствует и иногда даже ставит под сомнение ценность обучения.

Требования и интенсивность работы также могут поставить под угрозу профессиональную идентификацию. Слишком большая интенсивность в сочетании с непризнанием своих усилий может привести к ощущению эксплуатации и, следовательно, угрозы своей идентичности. Те, кому удается взять на себя ответственность благодаря доверию коллег, чаще воспринимают условия труда как средство обучения, позволяющее им ценить себя как профессионалов, развивая при этом чувство уверенности в себе. Обретение автономии и пространства для маневра, по-видимому, способствует облегчению тяжёлых условий труда, если учеников добиваются признания в компании.

Эти различные факторы характеризуют хрупкое равновесие, на котором ученики в сфере розничной торговли строят свою профессиональную идентичность. Но в любой момент легко можно переключиться с идентификации на дистанцирование от профессии, что может привести к смене карьеры. На рабочем месте не всегда легко найти баланс. Сохраняется заблуждение относительно реального статуса ученика, который иногда считает себя полноценным сотрудником, а иногда - человеком, проходящим обучение. Этот феномен отражает всю сложность учёбы и практики, которая имеет тенденцию открывать двери для использования учеников как дешевой рабочей силы, посвященной выполнению самых неблагодарных задач. Если этот баланс имеет тенденцию к смещению в отрицательную сторону, то развитие профессиональной идентичности учеников ставится под угрозу. Результаты этого исследования также показали, что ученики часто проявляют инициативу и применяют стратегии адаптации, чтобы улучшить свою профессиональную жизнь и, конечно, своё обучение.

\section{ЛИТЕРАТУРА}

1. Алонзо, П. (1998). Отношение к работе и занятости кассиров в большом количестве. Маленькие стратегии для большой добродетели. Работа и занятость, 76, 37-51.

2. Голлак, М., Волков, С., Рай Вольф, Л. (2014). Условия труда (3-е изд.). Пэрис: открытие.

3. Гэдри, Н., Джани-Катрис, Ф., и Перно-Лематтр, М. (2005). Условия труда неквалифицированных сотрудников. В Д. Меда и Ф. Веннат (ред.), Неквалифицированный труд. Перманансы и парадоксы (стр. 182-196). Париж: Открытие.

4. Дармон, М. (2016). Социализация. Париж: Арман Колин.

5. Дежур, К. (2000). Работа, умственный износ: от психопатологии к психодинамике труда. Париж: Баярд.

6. Дженкинс, Р. (2008). Социальная идентичность. Лондон: Рутледж.

7. Дубар, К. (1998а). Социализация. Построение социальной и профессиональной идентичности. Париж: Арман Колин.

8. К Каддури, М., Леспессаль, К., Майлебуи, М., Басконселлос, М. (2008). Проблема идентичности в работе и обучении. Материалы исследований, состояние практики и библиографические исследования. Париж.

9. Коэн-Скали, В. (2001). Профессиональная социализация и трансформации личности среди молодежи // Психология труда и организации, 7 (3-4), $257-$ 276.

10. Меркюр, Д., Вултур, М. (2010). Смысл работы. Новая производственная модель и рабочий дух в Квебеке. Квебек: Издательство Лавальского университета.

11. Фрей, А.-М., Пикуло, С. (2010). Диагностика профессиональной идентичности: важный аспект качества в работе. 0бзор менеджмента, 8, $72-88$.

12. Хохшильд, А.Р. (1983). Управляемое сердце: коммерциализация человеческого чувства. Беркли: Калифорнийский университет.

13. Чармаз, К. (2001). Качественное интервьюирование и анализ обоснованной теории. В Ж.Ф. ГУБРИМ и др. Ж.А. Гольштейна (ред.), Справочник по интервью исследований. Контекст и методы. (стр. 675-694). 